\title{
Powered by Assemblage: \\ Language for Multiplicity
}

We live in a world that tends to be organised by binaries: language/society; material/discursive; body/mind; and human/non-human. Stepping outside these dualisms, I want to suggest an alternative way to look at the world that starts with multiplicity and focusses on relationships, connections, and processes. This alternative is assemblage: a multi-temporal, heterogenous arrangement of discourses, materialities, bodies, and affects, powered by desires and influenced by capitalist transformations (Deleuze and Guattari [1980]1987)). My own need to conceptualise and research multiplicities comes from my experience researching Cold Rushi in the Arctic: a moment of simultaneous, intertwined, on-going, enduring and contradictory processes and practices of transforming commons into commodities. These transformations include, for example, turning wild berries into superberries, or a night in the Arctic into a Northern Lights hunt. Examining the boom, bust, and buzz around these conversions, intensified by climate change and the global pandemic, requires an approach that opens up and keeps up both with the reasons and rhizomes of these transformations and their relationships.

Assemblage refers to both the act of assembling diverse elements - a car, people, cameras, driving, stories, a night, the Arctic - and to the arrangements of these elements for a specific purpose, such as a Northern Lights hunt. Importantly, it is the interaction between elements that allows the assemblage to become more than the sum of its parts. So, for example, simply putting people in a car with a camera on a dark Arctic night does not become a Northern Lights hunt without work. Rather, the elements must be brought together under particular conditions, made to function in specific ways to accomplish their conjoined capacities and goals. The role of discourse is vital here. Narratives about Northern Lights, modifications of tourism interaction scripts, injections of Finnish place names, entertaining stories while passing time, are all part of the discursive work aimed at weaving the various elements into an unique Northern Light hunt product. Discourse is needed to make Arctic tourism products coherent, providing a framework for interpretation and the genre of action. Discourse enables these products to function by re-territorialising relevant elements from their previous contexts and de-territorialising them in the context of Arctic tourism. Through re- and de-territorialisation, a productive assemblage produces new means of expression, spatial and temporal organisations, and behaviours, all potential ingredients of economic transformations. Reand de-territorialising processes are, as Guattari and Deleuze ([1980]1987), remind us in their critique of capitalism, a core process in capitalism, which can be productively examined with an assemblage approach.

For me, the key advantage of using assemblage to study Cold Rush is that it does not flatten the complex historical, political, and economic processes that create possibilities and tensions for the commodification of commons, nor does it disregard the ways in which these transformations are intertwined with historical, ongoing, and anticipated economic, political, and personal interests. Rather than focusing on any one singularity, assemblage concentrates on a moment when various processes co-function. Assemblage thus bypasses old binaries between material/discursive, form/function, and language/society by shifting the focus to relationships and interactions between elements. As a research design, assemblage avoids zooming in on a single dot in isolation and instead helps map various dots to examine what they produce by looking at relationships, interactions, and movements between them.

Assemblage approach is not alone in its attempt to go beyond binaries to connect multiple perspectives and frameworks. Various prefixes ranging from bi-, multi-, trans-, super-, post-, and 
de-, together with a shift from static nouns to active processes (e.g., from language to languaging) in language research and elsewhere show a need and desire to expand research from one to many and from fixed to movement (e.g. Reyes 2014, Pavlenko 2019, Pennycook 2016, Pietikäinen et. al. 2008). For example, in discourse studies, the framework of nexus analysis, developed by Ron Scollon and Suzie Wong-Scollon (2004), brings together ethnography, interactive sociolinguistics, and discourse analysis to examine social action. Similar to the idea of assemblage, in nexus analysis, too, the key idea is that the co-function of different elements - the body, discourses, the interaction order - makes a social action. Also, the widely used three-dimensional framework by Norman Fairclough (1992) brings together text analysis with in-depth contextual analysis of discourse practices and social conditions to examine multi-dimensional discourse. We can also argue that multi-sited ethnography connects everyday practices and experiences with historical, political, economic, and cultural processes (Heller, Pietikäinen and Pujolar 2018).

In my view, assemblage thinking moves beyond these frameworks and produces alternatives ways to research dynamics of language and society. One critical move is an ontological shift from binaries and dichotomies to a more complex terrain of multiplicity, heterogeneity, convergence, and flows. While dualism and binaries may well continue to be a useful structure in some contexts, they still prove limiting in another contexts. Assemblage thinking respond to the need for conceptual and methodological tools that are apt for examining real-life, complex, messy, intertwined, and ongoing processes and constellations. Focusing on the particularities of specific context or action can be useful but this alone is not enough: We also need to map, trace, connect, and explain the different forces and elements that together produce the object under study. In practice, assemblage may require working across sections, perspectives, and positions of knowledge production, finding unexpected allies or employing concepts that, from the start, see our research objects and knowledge production as heterogenous products of joint forces, or an assemblage. Assemblage continues to be understood and applied in multiple ways to a wide range of topics, such as art and sports (Cantarella, Hegel \& Pietikäinen 2018), language ideologies (Kroskrity 2018), academic writing (Henderson, Honan and Loch 2016) and language learning and multilingualism (Bylund and Björk-Willén 2015). The various applications share a desire to go beyond fixed, isolated and compound understandings of concepts such as language, identity, community, learning, and to expand and engage with all those elements that together seem to produce the object of our inquiry.

Another productive effect of assemblage thinking is multi-temporality. Historical accounts, often drawing on work by Foucault ([1969]2013), have shown how what appears to be necessary constrains and conditions of our experiences are in fact historically contingent. Assemblage expands beyond the past by including present and possible temporalities in our concepts and practices (Deleuze ([1968]1994). For example, Cold Rush both leans on and feeds into part, present and future temporalities. When transforming commons into commodities, traditional knowledge about land and weather is used in foraging and narrating and re-valuing products. Speculation, however, is the most alluring temporality in the Cold Rush. It is used to make sense of and justify decisions and investments made in the present. Speculation around a commodity that uses common's boom and bust cycles is a key temporality for people and businesses making a living out of the Rush. This pattern is particularly palpable in the extractive mining industry where nostalgia for the permanent jobs of the industrial era is used in speculation for re-opening old mines under current global conditions (Pietikäinen and Allan, 2021).

Cold Rush banks on a speculative future involving commons. As the "pureness" of land, air, and water becomes increasingly rare, the boom will grow. The current bust caused by the global pandemic is speculated to be only temporary. The hopeful buzz about next season has already started, fueled the historical accounts of how people and companies have survived before, which 
feeds into a speculative positive future for the rush. Memories of past recoveries have become a source of hope, and speculation is a tool to move beyond the past and present to possible and potential futures. Deleuze and Guattari ([1980]1987) note that speculation is a specific modality of capitalism. Once again, the role of discourse is vital, given that speculation works though discourse, including multimodal explanations, future-oriented narratives, and affective language. This makes speculation an especially productive temporality for language researchers.

Assemblage has great potential to push forward research on complex interactions between language and society. It has the capacity to override the boundaries of any particular code, category, or perspective, which may colonialize our systems of thinking or focus of analysis. Assemblage challenges language researchers to engage with multiple perspectives, emergent practices, and speculative futures. In my experience, assemblage both helps and forces thinking beyond language, to take temporality as an important context, and to engage with multiple perspectives and knowledges. In my research on Cold Rush, assemblage has been imperative for keeping an ontological eye on multiplicity and complexity. It has helped me shift the focus from binaries to connections and relationships, while accounting for the politics of organization of various elements and the various temporalities relevant to the transformation that I have examined. At the same time, assemblage can be a mind-blowing, challenging concept that opens up to so many directions that it becomes difficult to imagine at the grassroots level of a research project. An antidote is to keep assemblage situated. The power of assemblage is intertwined with specific political economies, local social histories, and discursive practices. This translates, in my case, to combining assemblage thinking with Foucauldian discourse analysis and ethnography. With these perspectives, assemblage becomes simultaneously grounded and flowing.

Language does so much more than it can say. Yet, it does not do this alone. Here is where assemblage can step in and inspire new thinking and research on dynamics between language and society. Such encounters engage with the multiplicity of the social issues we examine; their material, affective and discursive dimensions, their relative stability and dynamics, their different relationships and temporalities, and their embeddedness in power relations. Seeing language as part of assemblage is one alternative to examine the power of language, one that opens up new possibilities, alliances, and solutions. 
Björk-Willen, Polly, and Anna Bylund. 2015. "Multilingual becoming in reading: A picture storybook reading-assemblage in early years education." In Early Years Second Language Education: edited by Sandie Mourão, and Mónica Lourenço. London: Routledge. pp. 78-92.

Cantarella, Luke, Sari Pietikäinen, and Christine Hegel. 2018. "Ice Time: Transversal Knowledge Production Between Hockey And Art". Journal Of The American Anthropological Association. http://www.americananthropologist.org/2018/11/01/ice-time-transversal-knowledge-productionbetween-hockey-and-art/.

Deleuze, Gilles, and Félix Guattari. 1980/1987. A Thousand Plateaus: Capitalism And Schizophrenia. London: Bloomsbury Academic.

Deleuze, Gilles. 1968/1994. Difference And Repetition. London: Continuum.

Fairclough, Norman. 1992. Discourse And Social Change. Cambridge: Polity Press.

Foucault, Michel. 1969/2013. Archaeology Of Knowledge. Hoboken: Taylor and Francis.

Heller, Monica, Sari Pietikäinen, and Joan Pujolar. 2018. Critical Sociolinguistic Research Methods. London: Routledge.

Henderson, Linda, Eileen Honan, and Sarah Loch. 2016. "The Production Of The Academicwritingmachine". Reconceptualizing Educational Research Methodology 7 (2). doi:10.7577/rerm.1838.

Kroskrity, Paul V. 2018. "On Recognizing Persistence In The Indigenous Language Ideologies Of Multilingualism In Two Native American Communities". Language \& Communication 62: 133144. doi:10.1016/j.langcom.2018.04.012.

Pennycook, Alastair. 2016. "Mobile Times, Mobile Terms: The Trans-Super-Poly-Metro Movement." Chapter. In Sociolinguistics: Theoretical Debates, edited by Nikolas Coupland, 20116. Cambridge: Cambridge University Press. doi:10.1017/CBO9781107449787.010.

Pietikäinen, Sari, and Kori Allan. 2021. "Jobs for Life? Mining Temporalities in a Transforming Arctic Periphery." In Language, Global Mobilities, Blue-collar Workers and Blue-Collar Workplaces edited by Gonçalves, Kellie, and Helen Kelly-Holmes. London: Routledge. pp. 27-48.

Pietikäinen, Sari, Riikka Alanen, Hannele Dufva, Paula Kalaja, Sirpa Leppänen, and Anne Pitkänen-Huhta. 2008. "Languaging In Ultima Thule: Multilingualism In The Life Of A Sami Boy". International Journal Of Multilingualism 5 (2): 79. doi:10.2167/ijmb083.0.

Pavlenko, Aneta. 2019. "Superdiversity and why it isn't: Reflections on terminological innovation and academic branding." In Sloganization in language education discourse: Conceptual thinking in the age of academic marketization edited by Schmenk, Barbara, Stephan Breidbach, and Lutz Küster. 42-168. Bristol: Multilingual Matters

Reyes, Angela. 2014. "Linguistic Anthropology In 2013: Super-New-Big". American Anthropologist 116 (2): 366-378. doi:10.1111/aman.12109. 
Scollon, Ronald, and Suzie Wong Scollon. 2004. Nexus Analysis. London: Routledge. 